\title{
РОЛЬ ИНТЕРАКТИВНЫХ МЕТОДОВ В ОБУЧЕНИИ РУССКОМУ КАК ИНОСТРАННОМУ'
}

\section{THE ROLE OF INTERACTIVE METHODS IN TEACHING RUSSIAN AS A FOREIGN LANGUAGE}

\section{F. Autleva \\ L. Bzegezheva}

Summary: The article substantiates the theoretical prerequisites for teaching Russian as a foreign language, taking into account the ideas of intercultural competence. In this regard, the author substantiates the terminological content of the concept of «competence» within the framework of the problem under consideration. The most significant, in his opinion, principles of the formation of intercultural competence in the context of teaching Russian as a foreign language are put forward and described. Based on the understanding of the problems of implementing these principles, the role of educational technologies is noted, special attention is paid to the justification of the place of interactive methods and forms in teaching RCT. Based on the experience of pedagogical activity, the teaching potential of individual interactive methods is analyzed, their role in the formation of intercultural competence is emphasized. Specific methodological approaches to their application are described. The methodology of developing virtual excursions in Russia is described, the first stage of which was surveys of students (including an online survey) studying RCT, according to their cultural preferences, which places they would like to see, both in Russia as a whole and in the city where the university is located directly. Interactive methods and forms of training are shown to be the most optimal. The methodology of using virtual excursions correlated with both Russian history and culture, as well as with the traditions of the countries of residence of foreign students is described, which will allow applying a whole set of exercises for the development and evaluation of language, country studies, speech, etc. skills. It shows the purposeful education of respect for the cultures of different countries, the development of tolerance, focus on future intercultural dialogue, etc. Of no small importance, in the opinion of the authors, is the possibility of accessible training and free use of this method in the organization of distance learning during the pandemic.

Keywords: teaching Russian as a foreign language, intercultural competence, principles and technologies of teaching, the principle of intercultural interrelation, the principle of taking into account the possible intercultural "overlap", intersubjective interaction, interactive methods and forms, distance learning organizations, assessment of language skills.

\author{
Аутлева Фатима Аминовна \\ К.филол.н., дочент, Майкопский государственный \\ технологический университет \\ autlevaf@yandex.ru \\ Бзегежева Лариса Казбековна \\ К.филол.н., доцент, Майкопский государственный \\ технологический университет \\ bzegezheva@yandex.ru
}

Аннотация: В статье обоснованы теоретические предпосылки преподавания русского как иностранного с учётом идей межкультурной компетенции. В этой связи автором обосновано терминологическое наполнение понятия «компетенция» в рамках рассматриваемой проблемы. Выдвинуты и описаны наиболее значимые, на его взгляд, принципы формирования межкультурной компетенции в контексте обучения русскому как иностранному. На основе осмысления проблем реализации данных принципов отмечена роль образовательных технологий, особое внимание при этом уделено обоснованию места интерактивных методов и форм при обучении РКИ. С опорой на опыт педагогической деятельности проанализирован обучающий потенциал отдельных интерактивных методов, подчёркнута их роль в формировании межкультурной компетенции. Описаны конкретные методические подходы к их применению. Описана методика разработки виртуальных экскурсий по России, первым этапом которой стали опросы студентов (в том числе и онлайн-опрос), изучающих РКИ, по их культурным предпочтениям, какие места они хотели бы посмотреть, как в целом в России, так и в городе, где непосредственно находится вуз. Наиболее оптимальными показаны интерактивные методы и формы обучения. Описана методика применения виртуальных экскурсий, соотнесённых как с российскими историй и культурой, так и с традициями стран проживания иностранных студентов, что позволит применить целый комплекс упражнений по развитию и оценке языковых, страноведческих, речевых и др. умений. Показано целенаправленное воспитание уважительного отношение к культурам разных стран, развитие толерантности, нацеленности на будущий межкультурный диалог и т.п. Немаловажное значение, на взгляд авторов, имеет возможность доступной подготовки и свободного использования данного метода при организации дистанционного обучения в период пандемии.

Ключевые слова: обучение русскому как иностранному, межкультурная компетентность, принципы и технологии обучения, принцип межкультурной взаимосвязи, принципа учёта возможного межкультурного «наложения», межсубъектное взаимодействие, интерактивные методы и формы, организации дистанционного обучения, оценка языковых умений.

Грант Министерства просвещения Российской федерации на реализацию мероприятий, направленных на полноценное функционирование и развитие русского языка, ведомственной целевой программы «Научно-методическое, методическое и кадровое обеспечение обучения русскому языку и языкам народов Российской Федерации» подпрограммы «Совершенствование управления системой образования» государственной программы Российской Федерации «Развитие образования» 
$\mathrm{P}$ етроспективный анализ проблемы преподавания русского языка как иностранного (далее - РКИ) позволяет говорить о нескольких сменяющих друг друга и взаимосвязанных научных концепциях, оказавших непосредственное влияние на современное видение образовательного процесса в области РКИ.

Так, досоветский период по определённой аналогии с концепцией «научных революций» Т. Куна [5] можно рассматривать как «допарадигмальный» [см., например, $1,7,9]$, в рамках которого преподавание РКИ представало исключительно в прикладном аспекте. По мнению отдельных учёных (А.Ю. Бондаренко, Т.И. Капитонова, И.П. Лысаков, А.Н. Щукин и др.), на допарадигмальном этапе в большей степени получили развитие системно-грамматическое и практическое направления в обучении РКИ. Однако главным мы считаем тот факт, что именно в данный период был дан толчок осмыслению таких методов обучения, в которых коррелируются компоненты интуитивно-имитативного, сознательно-сопоставительного и диалогового подходов. Наиболее значимыми идеями, не утратившим актуальности и на современном этапе являются:

1. признание значения лингвокультурологического материала в преподавании РКИ;

2. предложение о применении любых заданий в рамках ситуативно-обусловленного коммуникативного контекста с приданием особой значимости моделированию при обучении схожей с естественной языковой среды.

Непосредственно в парадигмальный период (см. труды В.Г. Костомарова, О.Д. Митрофановой, Е.И. Пассова и др.) получила активное обсуждение и применение теория обучения иностранному языку на коммуникативной основе, в связи с чем принцип активной коммуникативности стал признаваться также и ведущим принципом обучения РКИ $[6,8]$.

В рамках исследуемой нами проблемы важно подчеркнуть, что данный принцип в перспективе стал соотноситься с функциональным подходом к отбору языкового материала, его ситуативно-тематического представления и применения в прагматико-речевом контексте, в связи с чем в последние годы стали активно обсуждаться вопросы поиска путей и методов формирования межкультурной компетенции при организации обучения иностранным языкам, в том числе и РКИ $[10,11,13]$.

Не ставя своей целью глубоко анализировать теоретические исследования по обоснованию термина «компетенция», поясним , что в работах И.А. Зимней, Е.О Ивановой, И.М. Осмоловской, А.В. Хуторского и др. понятие «компетенция» связывается с определённым кругом вопросов, в которых будущий или действующий специалист свободно ориентируется, применяя при этом необходимые знания, умения и наработанный минимальный опыт, что предопределяет возможность умело и осознанно действовать в различных коммуникативных, социальных, профессиональных и т.п. ситуациях [см., например,4] .

Формирование межкультурной компетенции непосредственно в рамках обучения РКИ мы связываем с реализацией:

- принципа межкультурной взаимосвязи, которым определяется отбор материала культуроведческого содержания для применения в ситуативнотематических ситуациях общения на основе обсуждения схожих или представляющих взаимный интерес культурных традиций, артефактов и т.п. двух народов;

- принципа учёта возможного межкультурного «наложения», который обусловливает в деятельности преподавателя такой отбор обучающего материала, при котором осуществляется учёт возможной схожести отдельных языковых явлений, форм (в том числе, на уровне фонетики, графики и т.п.) в двух языках (родном и русском языке), что, однако, не коррелируется с их семантическим и культурологическим контекстами и искажает восприятие материала.

Реализация данных принципов самым непосредственным образом влияет на отбор и применение форм и методов преподавания РКИ. Среди основных технологий методики РКИ различают лично-ориентированные, проблемные, игровые, диалогичные, интерактивные и т.п. Последние, на наш взгляд, имеют особое значение в контексте формирования межкультурной компетенции при обучении русскому как иностранному.

Как считают многие исследователи, идея интерактивности (interact, interaction, англ.: «inter» - «взаимный», «act» - «действовать») применительно к дидактике основывается на идеях и достижений теорий систем телекоммуникаций [15], социологии [14], информатики [2] и др. В рамках педагогики понятия «интерактивный», «интерактивность» и др. стали применяться в рамках описаний методических подходов к обучению через межсубъектное взаимодействие (интерактивный - способный взаимодействовать или находиться в режиме диалога, полилога) [см., например, 3].

Данные интерактивные методы представляются наиболее перспективными в рамках решения проблемы формирования межкультурной компетенции. В этой связи с опорой на собственный педагогический опыт пред- 
ставим пример применения интегративных методов в виде групповой работы по созданию программ виртуальных экскурсий по городам и памятным местам двух стран.

Представим методические подходы, применённые при разработке виртуальных экскурсий по России. Первым этапом подготовки программ виртуальных экскурсий стали опросы студентов (в том числе и онлайн-опрос), изучающих РКИ, по их культурным предпочтениям, какие места они хотели бы посмотреть, как в целом в России, так и в городе, где непосредственно находится вуз. С учётом данных предпочтений были сформированы три программы по следующим темам («Познавай Россию», «Московский Кремль: история и современность», «Красоты Санкт-Петербурга», «Золотое кольцо России», «Сочи - столица курортов России», «От Домбая до Бермамыта») непосредственно при подготовке виртуальных экскурсий по России мы привлекали к их разработке студентов, носителей языка.

Они разрабатывали к каждому слайду диалоги, помогали составлять тематические словарики по тем или иным культурным артефактам и т.п. Преподаватель выступал как модератор, а также разрабатывал дополнительные задания, упражнения, которые не только были соотнесены с тематикой виртуальной экскурсии, но и опирались на описанные выше принципы формирования межкультурной компетенции.

При проведении экскурсии ребята-добровольцы также помогали, включаясь диалоги и объяснения (в том числе, и с применением технологии ZOOM). Непосредственно же по сопутствующим экскурсии заданиям с иностранными студентами работал преподаватель, предварительно составив матрицу оценивания в ходе виртуальной экскурсии их языковых, страноведческих, речевых и др. умений.

\section{Методические подходы при разработке виртуальных экскурсий по стране проживания иностранных студентов}

Подготовка к данной виртуальной экскурсии имела свою специфику. Её целью была комплексная проверка компетенций студентов, сформированных на определённом этапе изучения РКИ. Данные экскурсии готовили только иностранные студенты, объединившись в творческие подгруппы по 5-7 человек. Они должны были подготовить непосредственно на русском языке рассказы о культуре и традициях своего народа, сопровождая это слайдами, фото, видеоматериалами. Преподаватель и привлекаемые им студенты -носители языка выступали консультантами. Большую помощь оказывали также сотрудники библиотеки.

Большим достижением данного метода является то, что в течение нескольких занятий были заслушаны и оценены все студенты (преподаватель также предварительно составлял матрицу оценивания языковых, страноведческих, речевых и др. умений, сформированных уже к данному этапу обучения). По согласованию со студентами-иностранцами отдельные, наиболее интересные экскурсии предлагались через сетевой ресурс вуза и российским студентам.

Проведённые после серии виртуальных экскурсий контрольные срезы подтвердили эффективность применения данного интерактивного метода. Интересно при этом отметить, что часть экскурсий была затребована впоследствии представителями национальной диаспоры, а также управлением воспитательной работы вуза.

Таким образом, в целом, в рамках рассматриваемой проблемы можно сделать следующие выводы:

1. Изучение вопросов повышения качества РКИ обусловило закономерный переход от признания основным принципом методики РКИ изучение русского языка как элемента культуры к утверждению принципа изучения РКИ в тесной связи с формированием межкультурной компетенции. Это не только предопределяет более осознанное изучение языка, но и способствует социокультурной адаптации, упреждает возможные ошибки, обусловленные «наложением» межкультурных фонов, а зачастую и бытующими национальнокультурными стереотипами.

2. Наиболее оптимальными в данном направлении предстают интерактивные методы и формы обучения, в частности, описанная авторами методика применения виртуальных экскурсий, соотнесённых как с российскими историй и культурой, так и с традициями стран проживания иностранных студентов. Применение данного интерактивного метода позволяет применить целый комплекс упражнений по развитию и оценке языковых, страноведческих, речевых и др. умений. При этом идёт целенаправленное воспитание уважительного отношение к культурам двух стран, развитие толерантности, нацеленности на будущий межкультурный диалог и т.п. Немаловажное значение, на взгляд авторов, имеет возможность доступной подготовки и свободного использования данного метода при организации дистанционного обучения в период пандемии. 


\section{ЛИТЕРАТУРА}

1. Актуальные проблемы русского языка и методики его преподавания: традиции и инновации: сборник статей XVI Всероссийской научно-практич. конф. (Москва, 22 апреля 2016 года) /гл. ред. В.М. Шаклеин. - М.: Изд-во РУдН, 2016. - 317 с.

2. Воронкова 0.Б. Информационные технологии в образовании: интерактивные методы / О. Б. Воронкова. - Ростов н/Д: Феникс, 2010. - 315 с.

3. Гавронская Ю.Ю. «Интерактивность» и «интерактивное обучение»/ Ю.Ю. Гавронская // Высшее образование в России. -2008. - № 7. -С. 101-104.

4. Зимняя И.А. Ключевые компетенции - новая парадигма результата образования / И.А. Зимняя // Высшее образование сегодня. - 2003. - № 5. - С. 34-42

5. Кун Т. - Структура научных революций: пер. с англ.; сост. В.Ю. Кузнецов / Т. Кун. - М.: АСТ, 2003. -605 с.

6. Митрофанова О.Д. Методика преподавания русского языка как иностранного/ О.Д. Митрофанова, В.Г. Костомаров [и др.]. - М.: Русский язык, 1990. 270 c.

7. Оганесян А.Г. Проблемы и перспективы изучения в вузе русского языка как иностранного/ А.Г. Оганесян //Язык. Культура. 0бразование. - 2018. -№ 3.C. 49-52.

8. Пассов Е.И. Основы коммуникативной методики обучения иноязычному общению/ Е.И. Пассов. -М.: Русский язык, 1989. - 276 с.

9. Русский язык в поликультурном мире. (борник научных статей II Международного симпозиума (Ялта, 08-12 июня 2018 г.) /отв. ред. Е.Я. Титаренко. Симферополь: Ариал, 2018. - 472 с.

10. Семенова И.В. Тексты массмедиа как средство формирования межкультурной коммуникативной компетенции иностранных студентов/ И.В. Семенова// Педагогика. Вопросы теории и практики. -2020. -Т. 5. - № 2.- С. 259-264.

11. Сентябова А.В. Формирование межкультурной компетентности студентов-медиков при обучении РКИ/ А.В. Сентябова// Теория и практика преподавания русского языка как иностранного: достижения, проблемы и перспективы развития: материалы VII Междунар. науч.-метод. конф., Минск, 19-20 мая 2016 г. / редкол.: С.И. Лебединский (гл. ред.) [и др.]. — Минск: Изд. центр БГУ, 2016. - 226 с.

12. Сенченкова Е.В. Интерактивные формы обучения русскому языку как иностранному в медицинском вузе / Е.В. Сенченкова// Педагогическое образование в России. -2016. -№ 11.-С.96-99

13. Фролова 0.А. Мотивационный фактор формирования профессиональной межкультурной компетенции/ 0.А. Фролова// Вопросы педагогики. -2020. № 5-1. -C. 382-387.

14. Bernstein B. Social Class. Language and Socialization //Language and Social Context: Selected Readings. -Harmondsworth: Penguin, 1979. P.157-178

15. Melody W. Electronic Networks and Changing Knowledge. In «Communication Theory Today». Ed. Cambridge: Polity Press. 1995. -P. $254-273$. 